\title{
Analyzing the productivity of Korea and China's road freight transport industry: A nonparametric Malmquist approach
}

\author{
Hun-Koo Ha*, Sang-Won Lee* ${ }^{* *}$ Zhao Cheng ${ }^{* * *}$
}

\begin{abstract}
The objectives of this paper are to estimate the annual Malmquist TFP(total factor productivity) index of Korea and China's road freight transport with DEA(data envelope analysis) and to decompose the index into technical efficiency change and technology change. In the process of the estimation, we used labor, capital, and fuel as input factors and ton-km of road freight transport as output factor. The panel data of Korea and China's road freight transport industry from 1985 to 2004 are used. The results of the analysis show several points. First, there was no significant improvement in China's TFP growth before 1997, but there was continuous growth in TFP since 1997 because of constantly increasing domestic freight transport demand. Second, there was downward trend in Korea's TFP, especially there was a large reduction of productivity in 1998 because of the huge reduction of road freight transport demand during the period of the economic crisis. Third, the technology improvements play a significant role in the TFP growth and the technical efficiency had negative effects on the TFP growth of Korea. However, the technology improvements as well as the technical efficiency had positive effects on the TFP growth of China's road freight transport industry.
\end{abstract}

Keywords : DEA; Road freight transport; Malmquist index; TFP; Productivity

Submission Date: 8/25/2006 Acceptance Date: 10/4/2006

*Corresponding author: Professor, Asia Pacific School of Logistics, Inha University, Korea, Tel.: +82 328608232 ,

E-mail: hkha@inha.ac.kr

**Professor, Department of Economics, Inha University, Korea, E-mail: swlee@inha.ac.kr

${ }^{* * *}$ Student, Department of Logistics, Graduate School, Inha University, Korea 


\section{Introduction}

For the last several decades, Korea and china have showed high economic growth, which resulted in huge increments of freight transport. It is said that sustainable economic growth depends upon whether the economy provides efficiently with the capability of freight and passenger transport enough to accommodate increasing freight and passenger transport demand due to increasing economic activities. So Korea and China had invested large amount of resources into infrastructure such as road, railway, airport, and seaport. And also they had made great efforts to promote the productivity of freight transport industry including road freight transport.

These situations raise the necessity of positive research on the productivity of the freight transport industry. Total factor productivity (TFP) as a measure of overall productivity has been gaining recognition and acceptance not only for its theoretical correctness but also for its practicality among policy makers and economic analysts. Some governments have begun to include the TFP growth rate as a target in national development plans. It is also very important index to measure the performance of an industry. It is more useful to decompose the TFP growth into several factors such as technical efficiency growth and technology improvements.

In this paper, we get TFP growth rate of Korea and China's road freight transport industry by estimating the Malmquist TFP index with the DEA(data envelope analysis), which is a nonparametric approach in frontier approaches. On the basis of these estimations, we get decomposition of the TFP growth into technical efficiency growth and technology improvements. The annual time series input and output data of Korea and China's road freight transport industry from 1985 to 2004 are used to estimate the TFP index.

This paper consists of 5 chapters. In chapter 2, the concept and decomposition process of the Malmquist index are described, and the estimation method of the index with DEA and the used data are explained in chapter 3. The results of analysis are shown in chapter 4 and chapter 5 is the concluding remarks chapter.

\section{The Malmquist TFP index}

\subsection{The Malmquist TFP index}

The Malmquist index allows the changes in productivity to be broken down into technical efficiency change and technology efficiency change. The estimation process of the Malmquist TFP index can be explained by Fig. 1. In Fig. $1, \mathrm{~T}^{\mathrm{t}+1}$ and $\mathrm{T}^{\mathrm{t}}$ are production functions at $\mathrm{t}$ and $\mathrm{t}+1$ period. And the $\left(X_{t}, Y_{t}\right)$ and $\left(X_{t+1}, Y_{t+1}\right)$ are input and output at time period of $t$ and $t+1$. In order to estimate the Malmquist TFP index between two periods, we should get a distance function, $\mathrm{D}$, after measuring the frontier line by application of frontier approach. The distance function $\mathrm{D}$ is measured by the distance between actual production point and frontier line, so the distance function $\mathrm{D}^{t}\left(\mathrm{X}_{\mathrm{t}}, \mathrm{Y}_{t}\right)$ between the actual production point $\left(\mathrm{X}_{\mathrm{t}}, \mathrm{Y}_{\mathrm{t}}\right)$ at time $t$ and frontier line at time $t$ is defined as ob/oa. It means that the closer to 1 is the value of the distance function, the more efficient is the production 


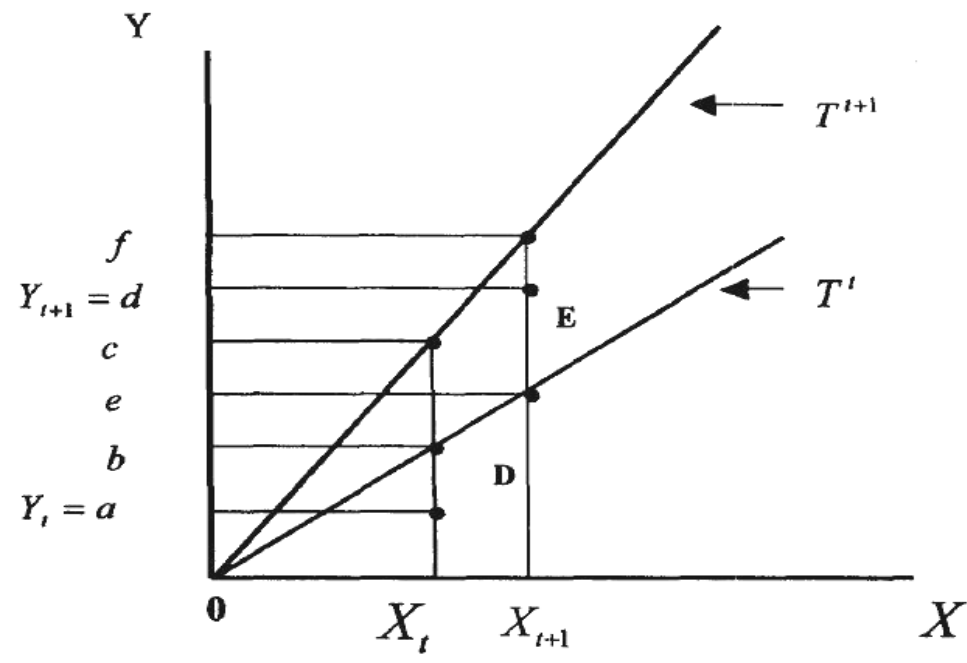

Fig. 1. The concept of Malmquist TFP index

The Malmquist TFP index(M) is estimated by distance function between the actual production point at time period $t+1,\left(X_{t+1}, Y_{t+1}\right)$ and the frontier line at time period $t$, that is, the cross period distance function, $\mathrm{D}^{\mathrm{t}}\left(\mathrm{X}_{\mathrm{t}+1}, \mathrm{Y}_{\mathrm{t}+1}\right)$ as shown at formula (1).

$\mathrm{M}^{\mathrm{t}}\left(X_{t}, Y_{t}, X_{t+1}, Y_{t+1}\right)=\frac{D^{t}\left(X_{t+1}, Y_{t+1}\right)}{D^{t}\left(X_{t}, Y_{t}\right)}=\frac{o d / o e}{o a / o b}$

At formula (1), $M^{t}>1$ indicates the productivity of period $\mathrm{t}+1$ is higher than that of period $\mathrm{t}$, since the reduction of the input vector of period $t+1$ to reach the frontier of period $t$ is higher than that applicable to the inputs of period t. On the other hand, $M^{t}<1$ indicates that productivity has decreased between period $t$ and $t+1$

Alternatively, it is possible to define the Malmquist index on the basis of the technology at period $\mathrm{t}+1$ as formula (2)

$\mathrm{M}^{\mathrm{t}+1}\left(X_{t}, Y_{t}, X_{t+1}, Y_{t+1}\right)=\frac{D^{t+1}\left(X_{t+1}, Y_{t+1}\right)}{D^{t+1}\left(X_{t}, Y_{t}\right)}=\frac{o d / o f}{o a / o e}$

In the above definitions, however, the value of the index changes according to the base-timetechnology of period $t$ or $t+1$. The method to solve the problem is to use the geometric mean of the indices of two base times. That method can minimize the problems caused by the change of base 
time $^{1}$. That index is showed in formula (3)

$M^{t+1}=\left[\frac{D^{t}\left(X_{t+1}, Y_{t+1}\right)}{D^{t}\left(X_{t}, Y_{t}\right)} \times \frac{D^{t+1}\left(X_{t+1}, Y_{t+1}\right)}{D^{t}\left(X_{t}, Y_{t}\right)}\right]^{1 / 2}=\left[\frac{o d}{o e} \times \frac{o b}{o a} \times \frac{o d}{o f} \times \frac{o c}{o a}\right]^{1 / 2}$

\subsection{The decomposition of the Malmquist TFP index}

Nishimizu and Page(1989) decomposed the Malmquist Index into technical efficiency change and technology change as in formula (4).

$M^{t+1}=\frac{D^{t+1}\left(X_{t+1}, Y_{t+1}\right)}{D^{t}\left(X, Y_{t}\right)}\left[\frac{D^{t}\left(X_{t+1}, Y_{t+1}\right)}{D^{t+1}\left(X_{t+1}, Y_{t+1}\right)} \times \frac{D^{t}\left(X_{t}, Y_{t}\right)}{D^{t+1}\left(X_{t}, Y_{t}\right)}\right]^{1 / 2}$

The technology change effect can be expressed by formula (5).

$T C^{t+1}\left(Y^{t+!}, X^{t+1}, Y^{t}, X^{t}\right)=\left[\frac{D^{t}\left(X_{t+1}, Y_{t+1}\right)}{D^{t+1}\left(X_{t+1}, Y_{t+1}\right)} \times \frac{D^{t}\left(X_{t}, Y_{t}\right)}{D^{t+1}\left(X_{t}, Y_{t}\right)}\right]^{1 / 2}=\left[\frac{o f}{o c} \times \frac{o c}{o b}\right]^{1 / 2}$

And the technical efficiency change can be expressed by formula (6).

$\operatorname{TEC}\left(Y^{t+!}, X^{t+1}, Y^{t}, X^{t}\right)=\frac{D^{t+1}\left(X_{t+1}, Y_{t+1}\right)}{D^{t}\left(X_{t}, Y_{t}\right)}=\frac{o d / o f}{o a / o b}$

From the analysis above, we can know that the growth of the TFP is composed of the technical efficiency change and the technology change. If the Malmquist productivity index is higher than 1, that is $M^{t+1}\left(X_{t}, Y_{t}, X_{t+1}, Y_{t+1}\right)>1$, it means that the total factor productivity increases because of the increment of technical efficiency or technology improvement.

\section{Data and estimation methodology}

\subsection{Data}

The data used in the process of estimating the Malmquist TFP index are composed of input data such as capital, labor and fuel, and output data which is the amount of road freight transport

${ }^{1}$ Fare et al. (1994) 
measured by ton-km. Labor is measured by the number of employees in the road freight transport industry. Capital is measured by the fixed assets estimated in 1985 prices. Fuel is measured by the used amount of coal-equivalent units.

The data for China's road transport industry are gained from Jiang(2003) and China's transport and Telecommunication Year Book. The data for Korea's road transport industry are from HunKoo Ha et al.(2002) and Korea's Statistical Yearbook of Construction and Transportation.

\subsection{Estimation method of Malmquist TFP index by the window-DEA application}

The standard Malmquist DEA method of Fare et als (1994) may produce unstable TFP indices because the sparse data will not be able to construct approximately "smoothed-surface" frontiers in each period. To overcome this problem, we used extended DEA methods, namely the TYW methods.

\section{The Three-year-window (TYW) DEA method}

The window DEA method was introduced by Charnes, Clark, Cooper and Golany (1985); Charnes, Cooper, Dieck-Assad, Golany and Wiggins (1985); and Charnes, Copper, Divine, Lopp and Stutz (1992). However, no study has applied the window DEA method to estimate the Malmquist index.

The window DEA technique is as follows. The panel of T cross-sections of data is divided into a series of shorter overlapping sub-panels, each having $\mathrm{S}$ (arbitrarily chosen) time periods, in which the first sub-panel contains periods $\{1,2, \ldots, S\}$; the second sub-panel contains periods $\{2,3, \ldots$, $\mathrm{S}+1\}$ and so on, until the last sub-panel which contains periods $\{\mathrm{T}-\mathrm{S}+1, \mathrm{~T}-\mathrm{S}+2, \ldots, \mathrm{T}\}$. The procedure is to construct a series of frontiers from the sub-panels, and these frontiers are used to calculate the distance functions needed to estimate the Malmquist TFP index. The advantage of this method is to relieve the degrees of freedom pressure when the number of inputs and output variables are large relatively to the number of analyzed objects.

In this paper, the width of the window was arbitrarily chosen at four. Thus, the first sub panel contains periods $\{1985,1986,1987,1988\}$, the second sub-panel contains periods $\{1986,1987$, $1988,1989\}$ and the last sub-panel contains periods $\{1997,1998,1999,2000\}$. Thus, in each year the frontier is constructed from 16 observations. We used the data of the year of 1988 as the frontier of the data from 1985 to 1988; the data of 1989 as the frontier of 1986 - 1989, and so on. Those methods were applied until the frontier of the data from 1997 to 2000 become the year of 2000 . Those methods are a kind of the Linear Programming(LP), which is described with the equations (7) to (10). This method is called as TYW(three year window)-DEA method which is a non parametric technique of linear programming. With this linear programming method, the Malmquist index can be estimated. 
$\left[D^{t+1}\left(X_{i, t+1}, Y_{j, t+1}\right)\right]^{-1}=F^{t+1}\left(X_{j, t+1}, Y_{j, t+1}\right)=\operatorname{Max} \theta$

$s \cdot t \cdot\left\{\begin{array}{l}\sum_{j=1}^{j} \lambda_{j+1} X_{j+1} \leq X_{j, t+1} \\ \sum_{j=1}^{j} \lambda_{j t+1} Y_{j+1} \geq \theta Y_{j, t+1} \geq 0, j=1, \ldots \ldots, J\end{array}\right.$

$\left[D^{t}\left(X_{j, t+1}, Y_{J, t+1}\right)\right]^{-1}=F^{t}\left(X_{j, t+1}, Y_{j, t+1}\right)=\operatorname{Max} \theta$

$\left[D^{t}\left(X_{i, t}, Y_{i, t}\right)\right]^{-1}=F^{t}\left(X_{j, t,} Y_{i, t}\right)=\operatorname{Max} \theta$.

$s \cdot t \cdot\left\{\begin{array}{l}\sum_{j=1}^{j} \lambda_{j t} X_{j t} \leq X_{i, t} \\ \sum_{i=1}^{j} \lambda_{j t} Y_{i t} \geq \theta Y_{i, t} \\ \lambda_{j t} \geq 0, J=1, \ldots \ldots J\end{array}\right.$

$\left[D^{t+1}\left(X_{i, t,} Y_{j, t}\right)\right]^{-1}=F^{t+1}\left(X_{i, t,} Y_{i, t}\right)=\operatorname{Max} \theta$

s.t. $\left\{\begin{array}{l}\sum_{j=1}^{j} \lambda_{j+1} X_{j+1} \leq X_{j, t} \\ \sum_{j=1}^{j} \lambda_{j+1} Y_{j+1} \geq \theta Y_{j, t} \\ \lambda_{j t} \geq 0, j=1, \ldots, J\end{array}\right.$ 
The above four steps of the LP method are very similar to standard DEA. With standard DEA LPs described from formula (10) to (12), we can measure the technical efficiency between the period of $t$ and $t+1$. In formula (11) and (12), the observation of the period $t$ can be compared to the technology used in the period $t+1$. In these LP systems, the value of the formula will be greater than or equal to one, if technical retrograde or progress has occurred. The above four LPs are required for each firm (or industry in our study) in each pair of adjacent years. Thus, if one has data on $\mathrm{K}$ firms over $\mathrm{T}$ time periods, one should solve $K \times(3 T-2)$ LPs to get the required firm level chained indices. $^{2}$ In order to estimate the scale efficiency in the transport industry, we need to estimate the distance variable related to the returns to scale, and add the constraint term, $\sum \lambda_{j T}=1$. By this method we can get $D\left(x_{t}, y_{t} \mid V, S\right)$ and the Malmquist equation described as follows:

$$
\left.\left.M_{t, t+1}=\frac{D_{t}\left(X_{t+1}, Y_{t+1}\right)}{D_{t+1}\left(X_{t+1}, Y_{t+1}\right)} \cdot \frac{D_{t}\left(X_{t}, Y_{t}\right)}{D_{t+1}\left(X_{t}, Y_{t}\right)}\right]^{1 / 2} \cdot \frac{D_{t+1}\left(X_{t+1}, Y_{t+1} \mid V, S\right)}{D_{t}\left(X_{t}, Y \mid V, S\right)} \cdot \frac{S_{t}\left(X_{t}, Y_{t}\right)}{S_{t+1}\left(X_{t+1}, Y_{t+1}\right)}\right]^{1 / 2}
$$

When the real point is $(\mathrm{X}, \mathrm{Y})$, it is

$$
S(Y, X)=D(X, Y \mid V, S) / D(X, Y \mid C, S)
$$

\section{The empirical results}

\subsection{The road freight transport TFP analysis of Korea}

\section{The TFP change}

For the road transport TFP changes, there was an obvious downward trend except for the year of 1991, 1994, 1997, and 2000. To our surprise, there was a significant reduction of the TFP Malmquist index in 1998, to 0.472 , which can be explained that the volume of output (unit is measured tonnage ${ }^{2}$ kilometer) dropped rapidly from 222.19 to 93.87 units.

\section{The technology change and technical efficiency change}

From Table 1, we can recognize that the technology improvement plays a significant role in the TFP growth of road freight transport industry in Korea. Except in the years 1994, 1997, and 2000, the technical efficiency had a negative effect on the TFP growth. Since the deregulation of entry barriers in Korea's trucking industry, the scale of the trucking companies became smaller as the number of trucking companies have highly increased and the competition among those

${ }^{2}$ Coelli et al. (1998) 
became fiercer. The competition factor can be explained by the change of the pure technical efficiency index. The pure technical efficiency has been constantly decreasing except in 1991 . The other index, that is, the scale economy had slight positive effects on TFP compared to other indexes.

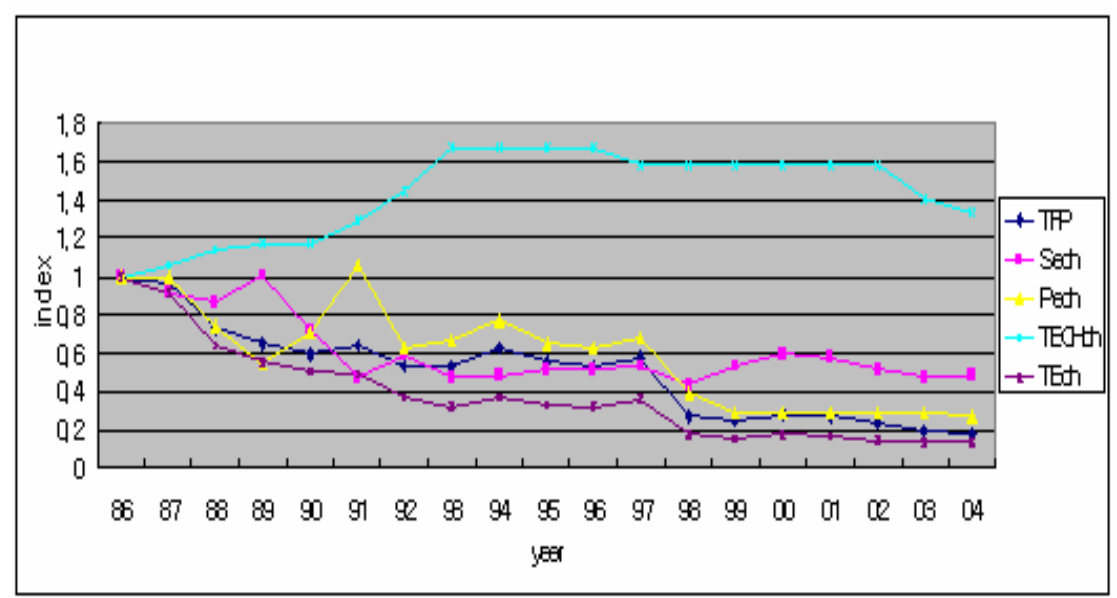

Fig. 2. Korea's road transport TFP and the decomposed indices

\subsection{The road freight transport TFP analysis of China}

\section{The TFP change}

As shown in Table 2, there was no significant improvement in TFP growth of China's road freight transport industry before the year 1997, but after that there was continuous growth until 2002. Because of the hugely increasing domestic demand according to the high speed of economic growth, China's domestic road freight transport TFP hasn't been greatly affected by the currency crisis of East Asia in 1998. Also, because of promoting economic growth with the government's reform policy and joining WTO, China's road freight transport market has been bigger than ever before.

\section{The technology improvement and technical efficiency change}

Similar to the Korean case, technology improvement made a significant effect on TFP growth that its indicators after 1995 showed significant progress and made positive effect on TFP growth. Especially, in the year 1994, 1996, 1997, and 2003, technology improvement showed positive effects on the TFP growth, but TFP declined mainly because of the negative effects of technical efficiency. In 1998, two indexes such as technology improvement and technical efficiency had positive effects on TFP growth. 
Table 1

Malmquist index of Korea's road freight transport and decomposition

\begin{tabular}{c|c|c|c|c|c}
\hline Year & TFP & $\begin{array}{c}\text { Scale } \\
\text { economy } \\
\text { (Sech) }\end{array}$ & $\begin{array}{c}\text { Pure technical } \\
\text { efficiency } \\
\text { (Pech) }\end{array}$ & $\begin{array}{c}\text { Technology } \\
\text { improvement } \\
\text { (TECHch) }\end{array}$ & $\begin{array}{c}\text { Techinical } \\
\text { Efficiency } \\
\text { (TEch) }\end{array}$ \\
\hline \hline 1987 & 0.969 & 0.911 & 1.000 & 1.064 & 0.911 \\
1988 & 0.754 & 0.954 & 0.736 & 1.073 & 0.702 \\
1989 & 0.888 & 1.163 & 0.745 & 1.025 & 0.866 \\
1990 & 0.918 & 0.709 & 1.294 & 1 & 0.918 \\
1991 & 1.075 & 0.654 & 1.486 & 1.107 & 0.971 \\
1992 & 0.839 & 1.253 & 0.598 & 1.121 & 0.749 \\
1993 & 0.992 & 0.806 & 1.067 & 1.153 & 0.86 \\
1994 & 1.172 & 1.026 & 1.142 & 1 & 1.172 \\
1995 & 0.892 & 1.053 & 0.847 & 1 & 0.892 \\
1996 & 0.964 & 1 & 0.964 & 1 & 0.964 \\
1997 & 1.075 & 1.047 & 1.083 & 0.948 & 1.134 \\
1998 & 0.472 & 0.812 & 0.583 & 0.997 & 0.473 \\
1999 & 0.888 & 1.226 & 0.724 & 1 & 0.888 \\
2000 & 1.137 & 1.12 & 1.015 & 1 & 1.137 \\
2001 & 0.971 & 0.971 & 1.000 & 1 & 0.971 \\
2002 & 0.882 & 0.882 & 1.000 & 1 & 0.882 \\
2003 & 0.812 & 0.932 & 0.980 & 0.889 & 0.913 \\
2004 & 0.904 & 1.004 & 0.944 & 0.953 & 0.948 \\
\hline
\end{tabular}

The increasing contribution of technology improvements to TFP growth seemed to result from the upgrade of highway quality and the expansion of highway-length due to growing infrastructure investment since the early 1990s. According to constant investments to highway, technology improvements will have a more important role in the TFP growth in road freight transport industry.

Compared with advanced countries, however, there is a large gap in the highway technique. The goals of the current highway freight transport in terms of safety cannot be met for the speed desired. Since the illegal modifications of truck vehicles to increase their capacity beyond legal limits are common, the government is also increasing the number of road checks to deter vehicles from carrying loads beyond their legal limits. However, the effectiveness of these checks is reduced by the transportation companies' unwillingness to cooperate. Another problem pertains to the vehicle used for freight transportation, which are usually open-backed trucks covered only by tarpaulins. While using these vehicles can reduce the vehicle price, the costs incurred from the loss and damage of goods are significant. So the problems with technology application remain obvious and frustrating to highway freight transport management. 


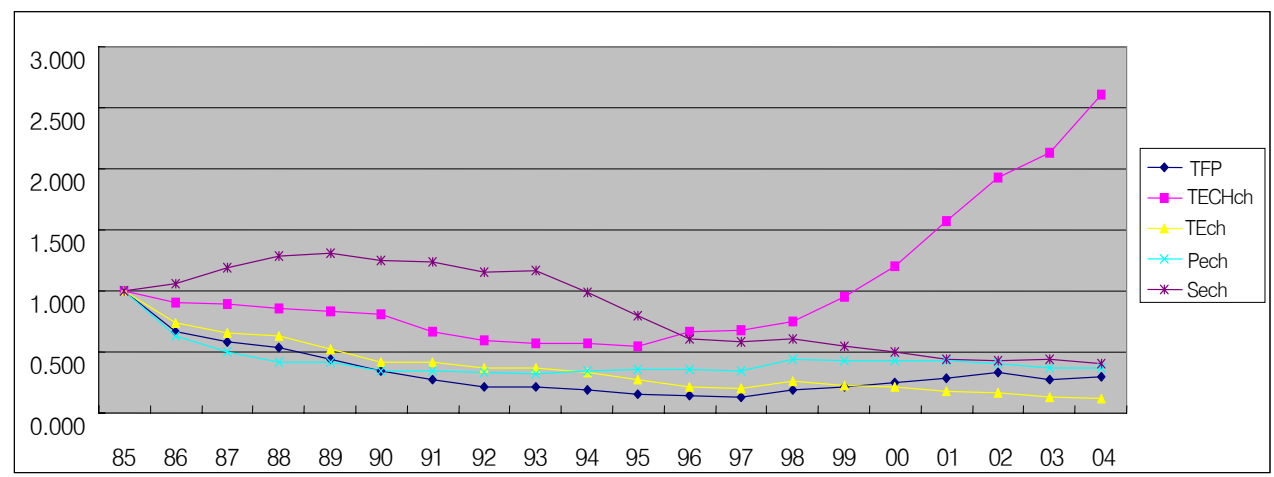

Fig. 3. China's road transport TFP and the decomposed indices

The index of scale economy was constantly decreasing after the year 1989, which means that the reform policy of China contributed to increments of the number of trucking companies.

\section{Conclusion and implications}

The objective of this paper is to analyze the evolution of productivity in the road freight transport industries of Korea and China by breaking down productivity growth into changes in technology and technical efficiency. In order to achieve this purpose, we used the concept of Total Factor Productivity and the Malmquist productivity index, which can be estimated with the DEA nonparametric frontier approach.

This study is the provision of valuable information on productivity growth in China road freight transport. We applied the new extended Malmquist DEA TFP methods to the panel data on freight transport industries in Korea and China. We estimated the TFP growth, the technical efficiency change index and the technology improvement index.

We find that before 1997, there was no significant improvement to TFP growth, but after 1997 there was a continuous growth until 2002. Because of huge increment of China's domestic freight transport demand according to the high speed of economic growth, China's domestic road transport TFP hasn't been greatly affected by the currency crisis, compared to Korean case.

Similar to the Korean case, the technology improvements made a significant effect on the TFP growth of China's freight transport industry. The level of its effect on China's TFP growth was higher than that of Korea since the middle of the 1990s mainly because of highway investment. This means that most of increasing productivity in both Korea and China is due to improvements in technology and not due to more efficient behavior in road freight transport industry. This would suggest that further steps need to be taken to substantially improve efficiency in the road transport industry. 
Table 2

Malmquist index of China's Road freight transport

\begin{tabular}{|c|c|c|c|c|c|}
\hline Year & TFP & $\begin{array}{c}\text { Technology } \\
\text { improvement } \\
\text { (TECHch) }\end{array}$ & $\begin{array}{c}\text { Techinical } \\
\text { Efficiency } \\
\text { (TEch) }\end{array}$ & $\begin{array}{c}\text { Pure technical } \\
\text { efficiency } \\
\text { (Pech) }\end{array}$ & $\begin{array}{c}\text { Scale economy } \\
\text { (Sech) }\end{array}$ \\
\hline 1986 & 0.668 & 0.899 & 0.743 & 0.631 & 1.059 \\
\hline 1987 & 0.876 & 0.991 & 0.884 & 0.783 & 1.119 \\
\hline 1988 & 0.923 & 0.958 & 0.963 & 0.848 & 1.088 \\
\hline 1989 & 0.816 & 0.978 & 0.834 & 0.989 & 1.016 \\
\hline 1990 & 0.773 & 0.972 & 0.795 & 0.832 & 0.957 \\
\hline 1991 & 0.801 & 0.818 & 0.979 & 0.994 & 0.985 \\
\hline 1992 & 0.797 & 0.895 & 0.891 & 0.957 & 0.931 \\
\hline 1993 & 0.974 & 0.964 & 1.010 & 0.994 & 1.016 \\
\hline 1994 & 0.904 & 1.002 & 0.902 & 1.060 & 0.851 \\
\hline 1995 & 0.785 & 0.951 & 0.825 & 1.034 & 0.798 \\
\hline 1996 & 0.930 & 1.214 & 0.766 & 1.011 & 0.758 \\
\hline 1997 & 0.954 & 1.023 & 0.933 & 0.968 & 0.963 \\
\hline 1998 & 1.457 & 1.102 & 1.322 & 1.260 & 1.050 \\
\hline 1999 & 1.129 & 1.269 & 0.890 & 0.977 & 0.910 \\
\hline 2000 & 1.151 & 1.274 & 0.903 & 1.009 & 0.895 \\
\hline 2001 & 1.137 & 1.303 & 0.873 & 0.987 & 0.884 \\
\hline 2002 & 1.149 & 1.228 & 0.936 & 0.945 & 0.990 \\
\hline 2003 & 0.820 & 1.103 & 0.743 & 0.919 & 1.028 \\
\hline 2004 & 1.098 & 1.223 & 0.898 & 0.990 & 0.907 \\
\hline
\end{tabular}

\section{References}

Asensio, J. and F. Trillas. 2005. The productive efficiency measurement and regulatory reform in Spanish suburban railways. Dep. Economic Aplicada, University of Autonoma de Barcelona, 08193 Bellaterrra.

Canto, P. and J. Lorenzo. 1999. Productivity, efficiency and technical change in the European railways. Kluwer Academic Publishers. 
Coelli, T.J. 1996. A guide to DEAP version 2.1: A data envelopment analysis(computer program.) CEPA Working Paper.

Coelli, T.J. and D.S. Prasada Rao. 1980-2000. Total factor productivity growth in agriculture: a malmqusit index analysis of 93 countries. Agricultural Economics, 32,115-134.

Estache, A. Tovar de la Fe. Beatriz, and Lourdes. Trujillo. 2004. Sources of efficiency gains in port reform: a DEA decomposition of a Malmquist TFP index for Mexico. Utilities Policy.

Ha, H. K. et al. 2003. TFP change analysis in Korea logistics industry. The Korea transport Institute.

Jiang, D. 2003. Study on the TFP of China transport industry. Dissertation of master degree in Shanghai Maritime Univ.

Kim, M. J. 2004. An analysis of the efficiency and productivity of Korean rail transit properties. Phd dissertation in Seoul National Univ.

Nghiem, H. and T. Coelli. 1999. The Effect of incentive reforms upon productivity : evidence from the vietnamese rice industry. School of Economic Studies, University of New England.

Odeck, J. 2000. Assessing the relative efficiency and productivity growth of vehicle inspection services: an application of DEA and Malmquist indices. European Journal of Operational Research. 126-501-514.

Worthington, A.C. 1999. Malmquist indices productivity change in Australian financial services. School of Economics and Finance. Queensland Univ. of Technology. Journal of International Financial Market.

Yao, C. and A. I. Ali. 2000. DEA Malmquist productivity measure: new insights with an application to computer industry. http://www.sciencedirect.com.

$\mathrm{Yu}$, S. D. Jiang and J. C. Lu. 2003. Productivity analysis of transportation in China. Journal of Tong Ji University. Natural Science.

Zellner, A. and N.S. Revankar. 1969. Generalized production functions. Review of Economic Studies. 36. 241-250.

Zhang, Y. and R. Bartels. The effect of sample size on the mean efficiency in DEA: with an application to electricity distribution in Australia. Sweden and New Zealand. Journal of Productivity Analysis. 9. 187-204 